\title{
ALTERNATIVAS PARA LA PROPAGACIÓN in vitro DE PLÁTANO VARIEDAD MAQUEÑO (Musa balbisiana AAB)
}

\author{
Hayron Fabricio Canchignia Martínez${ }^{1}$, Luis Ernesto Sigcha Sigcha ${ }^{2}$, José Pedro Toaquiza Soatunsig ${ }^{2}$, \\ Luis Edmundo Ramos Gavilanez ${ }^{1}$, Silvia Gicela Saucedo Aguiar ${ }^{1}$, Mercedes Susana Carranza Patiño ${ }^{3}$ y \\ Orly Fernando Cevallos Falquez ${ }^{4}$ \\ ${ }^{1}$ Unidad de Investigación Científica y Tecnológica, Facultad de Ciencias Agrarias, Universidad Técnica \\ Estatal de Quevedo. Av. Walter Andrade. Km 1,5 vía a Santo Domingo, C.P. 73. Quevedo. Los Ríos, \\ Ecuador.099300382. hfcanma@yahoo.es. \\ ${ }^{2}$ Unidad de Estudios a Distancias, Universidad Técnica Estatal de Quevedo. \\ ${ }^{3}$ Unidad de Investigación Científica y Tecnológica, Facultad de Ciencias Ambientales, Universidad \\ Técnica Estatal de Quevedo. \\ ${ }^{4}$ Unidad de Investigación Cientifica y Tecnológica, Facultad de Ciencias Pecuarias, Universidad Técnica \\ Estatal de Quevedo.
}

\begin{abstract}
RESUMEN
La reproducción in vitro es un método adecuado para la propagación masiva de plantas, esta técnica permite y garantiza una efectividad para la exportación comercial de genotipos seleccionados de musáceas como es el caso de plátano maqueño. Para el establecimiento aséptico de yemas a nivel in vitro, el mejor tratamiento de desinfección fue al $20 \%$ de cloro durante 20 minutos $+0.1 \%$ de bicloruro de mercurio por 10 minutos obteniendo el 100\% de explantes sanos. En la multiplicación la mejor respuesta se obtuvo con el tratamiento $5 \mathrm{mg} \mathrm{L}^{-1}$ de BAP $+1.2 \mathrm{mg} \mathrm{L}^{-1}$ AIA con un valor promedio de 2.5 brotes. La fase de desarrollo el mejor resultado se logró en el tratamiento compuesto por MS $+20 \mathrm{~g}$ sacarosa $+1 \mathrm{~g}$ de carbón activado. En la aclimatación y el enraizamiento ex vitro de las vitro plantas la respuesta se alcanzó en el sustrato tierra de campo obteniéndose mayor número de plantas adaptadas, con una longitud de raíz $6.1 \mathrm{~cm}$, el sustrato conformado por tamo de arroz originó un menor porcentaje de sobrevivencia.
\end{abstract}

Palabras claves: In vitro, genotipos, aséptico

\section{ABSTRACT}

The reproduction in vitro is a method adapted for the massive spread of plants, this technology allows and guarantees an efficiency for the commercial exportation of genotipos selected of musáceas since it is the case of banana maqueño. For the aseptic establishment of yolks to level in vitro, the best treatment of disinfection went to $20 \%$ of chlorine during 20 minutes + $0.1 \%$ of bicloruro of mercury in 10 minutes obtaining $100 \%$ of explantes healthy. In the multiplication the best response gave to itself with the treatment $5 \mathrm{mg} \mathrm{L}^{-1}$ of BAP $+1.2 \mathrm{mg} \mathrm{L}^{-1}$ AIA with a value average of 2.5 outbreaks. The phase of development the best result gave to itself in the treatment composed by MS $+20 \mathrm{~g}$ saccharose $+1 \mathrm{~g}$ of activated coal. The acclimatization and the enraizamiento ex vitro of the vitro you plant one gave the best response in the substratum field land obtained major number of adapted plants, with a length of root $6.1 \mathrm{~cm}$, the substratum shaped by fuzz of rice originated a minor percentage sobrevivencia.

Key words: In vitro, genotipos, aséptico

\section{INTRODUCCIÓN}

El cultivo de tejidos puede definirse como un conjunto de técnicas que permiten el desarrollo de cultivos deórganos, tejidos, células y protoplasmas en condiciones asépticas empleando medios nutritivos artificiales (Usui et al., 1996). Entre los métodos más utilizados en la regeneración de plantas se encuentran la organogénesis y embriogénisis que es un evento morfológico que se caracteriza por su desarrollo unipolar; en otras palabras es la formación de un primordio unipolar a partir de una yema con el subsecuente desarrollo de esta en un brote vegetativo, existiendo siempre una conexión entre los nuevos brotes y el tejido paterno (Izco, 1997). La organogénesis se manifiesta en forma directa e indirecta

Recibido: Septiembre, 2007. Aceptado: Enero: 2008.

Publicado como ARTÍCULO en Ciencia y Tecnología 1: 43-48. 2008. cuando los brotes se forman a partir de callos, que son masas de células obtenidas indiferenciadas producto de un crecimiento desorganizado de células obtenidas a partir de un determinado tejido directo cuando los brotes se forman directamente del explante sin formar callos. En ambos casos se requiere de una subsecuencia del medio de cultivo, ya que en general los medios que desarrollan brotes inhiben la formación de raíces y viceversa (Surga y Haddad, 1984), manifiestan que las auxinas influyen en el crecimiento de órganos vegetales estimulando la elongación o alargamiento de ciertas células e inhibiendo el crecimiento de otras, en función de la cantidad de auxina en el tejido vegetal y su distribución. Bidwell (1993), cita que en la mayoría de los procesos en que están implicadas las citoquininas 
estas participan junto con otras hormonas, especialmente auxinas. Así, ambas controlan el ciclo celular, actuando de forma sinérgica. Marassi (2004), indica las funciones de las citoquininas, son las siguientes: Estimulan la división celular y el crecimiento, inhiben el desarrollo de raíces laterales, rompen la latencia de las yemas axilares, promueven la organogénesis en los callos celulares, retrasan la senescencia o envejecimiento de los órganos vegetales, promueven la expansión celular en cotiledones y hojas. Esta investigación fue ejecutada por el Laboratorio de Biotecnología de la UTEQ, y tuvo como propósito, establecer un protocolo de propagación in vitro de esta variedad de Musa con la finalidad de obtener plantas con porcentajes altos de tolerancia o resistencia a virus, plagas y enfermedades y además, alcanzar aumentos en el tamaño del fruto y del rendimiento en relación a otras variedades comerciales existentes. Esto beneficiaría a los programas de mejoramiento genético de musáceas de cuyo fin es de incrementar la producción como es el plátano maqueño de esta manera satisfacer la demanda del mercado interno y externo.

\section{MATERIALES Y MÉTODOS}

\section{Material biológico}

El material genético usado en esta investigación fue recolectado en la Comuna Tsachila vía Puerto Limón del Cantón Santo Domingo de los Colorados.

\section{Reactivos}

\section{Reactivos para desinfección del material vegetativo:}

Bicloruro de mercurio, Tween 20, Hipoclorito de sodio, Sulfato de aluminio, Sulfato de alumbre, L-Cysteina.

\section{Reactivos de un medio de cultivo de Murashige y Skoog 1962 (MS):}

Macronutrientes, Micronutrientes, Vitaminas del MS, Azúcar, Bencilaminopurina (BAP), Acidoindolocetico (AIA), Agar, Carbón activado.

Fases de la investigación Diseño Experimental, Factores Estudiados y Tratamientos

\section{Establecimiento}

El objetivo de esta fase fue de determinar la mejor concentración de desinfectante a emplearse en la fase de establecimiento in vitro de plátano variedad maqueño, con los siguientes tratamientos: $\mathrm{T}_{1}=20 \%$ de $\mathrm{CINa} / 20$ $\min +0.1 \%$ de $\mathrm{HgCl}_{2} / 10 \mathrm{~min} ; \mathrm{T}_{2}=30 \%$ de $\mathrm{ClNa} / 15$ $\min +0.15 \%$ de $\mathrm{HgCl}_{2} / 7 \mathrm{~min} ; \mathrm{T}_{3}=40 \%$ de $\mathrm{ClNa} / 10$ min $+0.2 \%$ de $\mathrm{HgCl}_{2} / 5$ min. A los 21 días se evaluó mediante observación directa y se registró las siguientes variables: explantes sanos, contaminados, quemados y fenolizados. Se aplicó el diseño completamente al azar (DCA), con 3 tratamientos, 6 repeticiones. Cada repetición compuesto por 4 explantes.

\section{Multiplicación}

El objetivo de esta fase fue determinar la mejor concentración de citoquininas y auxinas empleadas en la multiplicación estableciendo los tratamientos: $\mathrm{T}_{1}=$ $\mathrm{MS}+2 \mathrm{mg} \mathrm{L}^{-1}$ de BAP $+0.5 \mathrm{mg} \mathrm{L}^{-1} \mathrm{AIA} ; \mathrm{T}_{2}=\mathrm{MS}+3$ $\mathrm{mg} \mathrm{L}^{-1}$ de BAP $+0.8 \mathrm{mg} \mathrm{L}^{-1} \mathrm{AIA} ; \mathrm{T}_{3}=\mathrm{MS}+4 \mathrm{mg} \mathrm{L}^{-1}$ de BAP + $1 \mathrm{mg} \mathrm{L}^{-1} \mathrm{AIA} ; \mathrm{T}_{4}=\mathrm{MS}+5 \mathrm{mg} \mathrm{L}^{-1} \mathrm{de} \mathrm{BAP}+$ $1.2 \mathrm{mg} \mathrm{L}^{-1}$ AIA. A los 28 días se realizó el registro de las variables número de brotes y altura, se utilizó una regla graduada con aproximación milimétrica. En esta fase se aplicó el diseño completamente al azar (DCA), con 4 tratamientos y 6 repeticiones cada repetición estuvo compuesta por 4 unidades experimentales.

\section{Desarrollo}

Esta fase se realizó antes de llevar a las vitroplantas a adaptación y enraizamiento en invernadero, en esta fase se evaluó diferentes tipos de sustratos. A continuación se detallan los tratamientos: $\mathrm{T}_{1}=\mathrm{MS}$ simple; $\mathrm{T}_{2}=\mathrm{MS}+20$ $\mathrm{g} \mathrm{L}^{-1}$ de sacarosa $+1 \mathrm{~g} \mathrm{~L}^{-1}$ de carbón activado; $\mathrm{T}_{3}=\mathrm{MS}$ $+30 \mathrm{~g} \mathrm{~L}^{-1}$ de sacarosa $+1 \mathrm{~g} \mathrm{~L}^{-1}$ de carbón activado; $\mathrm{T}_{4}=$ $\mathrm{MS}+40 \mathrm{~g} \mathrm{~L}^{-1}$ de sacarosa $+1 \mathrm{~g} \mathrm{~L}^{-1}$ de carbón activado. A los 21 días se evaluó, vigor y altura de las vitroplantas. Para medir la altura se utilizó una regla graduada en centímetros con aproximación a milímetros. El vigor se evaluó con una escala de: 0 a 2 bajo; 2 a 4 medio; 4 a 6 alto. Se utilizó el diseño completamente al azar (DCA), con 4 tratamientos y 6 repeticiones cada repetición estuvo compuesta por 4 unidades experimentales.

\section{Aclimatación}

En esta fase se llevó al invernadero las vitroplantas donde fueron colocadas en los sustratos, que a continuación se detalla: $\mathrm{T}_{1}=$ Tierra de sembrado; $\mathrm{T}_{2}=$ Arena; $\mathrm{T}_{3}=$ Tamo de arroz; $\mathrm{T}_{4}=$ Carboncillo. $\mathrm{A}$ los 21 días se evaluó: número de raíces, longitud de la raíz mayor, sobrevivencia, altura, diámetro. Se utilizó el diseño completamente al azar (DCA), con 4 tratamientos y 4 repeticiones cada repetición con 5 unidades experimentales. 


\section{RESULTADOS}

\section{Establecimiento aséptico}

Para el establecimiento aséptico de yemas de plátano maqueño, el tratamiento $20 \%$ de cloro, durante 20 minutos $+0.1 \%$ de bicloruro de mercurio por 10 minutos, presentó deferencia estadística significativa (*), con un $100 \%$ de explantes sanos libres de agentes contaminantes, comparado con el tratamiento $30 \%$ de cloro durante 10 minutos $+0.15 \%$ de bicloruro de mercurio por 7 minutos donde el porcentaje de contaminación fue de $54 \%$.

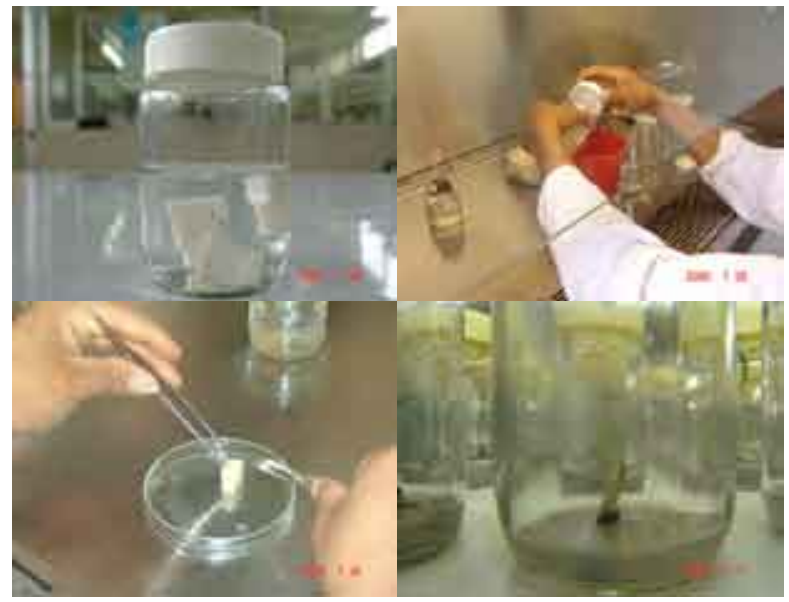

Figura 1. Desinfección del material vegetal y siembra en el medio de cultivo MS

En la variable de explantes no quemados los protocolos de desinfección de cada uno de los tratamientos fueron eficientes para el establecimiento aséptico de las yemas, siendo los tratamientos $\left(\mathrm{T}_{1} \mathrm{y}\right.$ $\mathrm{T}_{2}$ ), los cuales no provocaron ningún daño superficial a las yemas. La variable explantes no fenolizados no representó problema para el establecimiento aséptico de yemas de plátano maqueño. Cabe indicar que la presencia de los fenoles se pudo controlar utilizando agentes antioxidantes (sulfato, alumbre, L-Cysteina) para los respectivos tratamiento, como un método de control preventivo. Con respecto a la variable sobrevivencia se demostró diferencia estadística significativa, obteniendo así los mejores resultados para el tratamiento $\left(\mathrm{T}_{1}\right)$ con el mayor porcentaje de establecimiento aséptico para cada una de las yemas del plátano maqueño (Cuadro 1).

\section{Multiplicación}

En la regeneración de yemas adventicias para la fase de multiplicación el número de brotes alcanzada para los tratamientos evaluados no mostró diferencia estadística significativa, sin embargo, se detectó una mayor regeneración de brotes en el $\left(\mathrm{T}_{4}\right) 5 \mathrm{mg} \mathrm{L}^{-1} \mathrm{de}$ $\mathrm{BAP}+1.2 \mathrm{mg} \mathrm{L}^{-1} \mathrm{AIA}$.

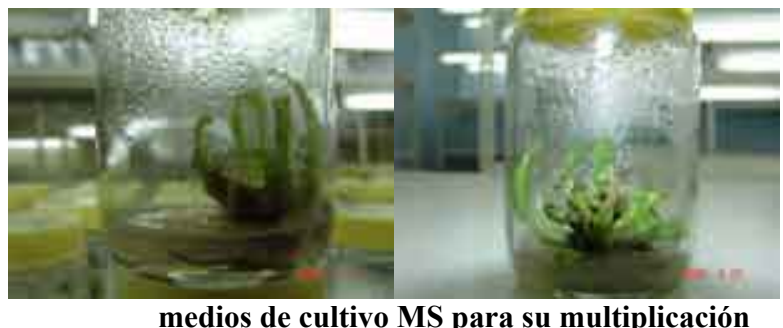

La variable longitud de brotes, no mostró diferencia estadística significativa, este efecto se dio por la utilización de reguladores de crecimientos en todos los tratamientos los cuales permiten regular el crecimiento en longitud de los brotes (Cuadro. 2).

\section{Desarrollo}

En el desarrollo de las vitroplantas, se demostró que para la variable vigor de las yemas, el testigo superó a los tratamientos suplementados con sacarosa y carbón activado, logrando obtener una mayor cantidad de vitroplantas de vigor alto listas para su aclimatación.

Cuadro 1. Promedios de explantes no contaminados, quemados, fenolizados y sobrevivencia, evaluados a los 21 días después de establecidos en el medio de cultivo aséptico de yemas de plátano variedad maqueño (Musa balbisiana)

\begin{tabular}{ccccc}
\hline TraTamientos & $\begin{array}{c}\text { Exp. No } \\
\text { Contaminados }\end{array}$ & $\begin{array}{c}\text { Exp. No } \\
\text { Quemados }\end{array}$ & $\begin{array}{c}\text { Exp. No } \\
\text { Fenolizado }\end{array}$ & Sobrevivencia \\
\hline $\mathrm{T}_{1}$ & $100.0 \mathrm{a}^{\dagger}$ & $100.0 \mathrm{a}^{\dagger}$ & $100.0 \mathrm{a}^{\dagger}$ & $100.0 \mathrm{a}^{\dagger}$ \\
$\mathrm{T}_{2}$ & $54.2 \mathrm{~b}$ & $100.0 \mathrm{a}$ & $100.0 \mathrm{a}$ & $54.2 \mathrm{~b}$ \\
$\mathrm{~T}_{3}$ & $50.0 \mathrm{~b}$ & $91.7 \mathrm{a}$ & $95.8 \mathrm{a}$ & $41.7 \mathrm{~b}$ \\
\hline C.V.\% & 31.22 & 12.12 & 5.98 & 24.56 \\
\hline
\end{tabular}

${ }_{\dagger}$ Promedios con letra distintas difieren estadísticamente según la prueba de Tukey $(\mathrm{p} \geq 0.05)$. 
Cuadro 2. Promedios de número y longitud de brotes, evaluados a los 28 días después de establecidos en el medio de cultivo aséptico de yemas de plátano variedad maqueño (Musa balbisiana)

\begin{tabular}{ccc}
\hline Tratamientos & Número de brotes & Longitud de brotes (cm) \\
\hline $\mathrm{T}_{1}$ & $2.208 \mathrm{a}^{\dagger}$ & $3.092 \mathrm{a}^{\dagger}$ \\
$\mathrm{T}_{2}$ & $2.250 \mathrm{a}$ & $3.112 \mathrm{a}$ \\
$\mathrm{T}_{3}$ & $1.833 \mathrm{a}$ & $2.320 \mathrm{a}$ \\
$\mathrm{T}_{4}$ & $2.458 \mathrm{a}$ & $3.283 \mathrm{a}$ \\
\hline C.V.\% & $31.82 \%$ & $53.89 \%$ \\
\hline
\end{tabular}

$\dagger$ Promedios con letra distintas difieren estadísticamente según la prueba de Tukey ( $\mathrm{p} \geq 0.05)$.

La variable altura alcanzada por las vitroplantas demostró diferencia estadística significativa, el testigo superó a los tratamientos suplementados con sacarosa y carbón activado siendo esto evidente que para obtener un buen desarrollo de las yemas de plátano maqueño no se requiere fuentes de carbohidratos extras para su crecimiento.

\section{Aclimatación}

Para longitud de la raíz mayor, el diámetro y altura de las plantas aclimatadas en el invernadero el análisis de varianza mostró diferencia estadística significativa, para los tratamientos en donde se utilizó tierra de sembrado, logrando un mayor promedio, siendo este el mejor tratamiento para la aclimatación de las vitroplantas y la regeneración de raíces y buen desarrollo del plátano maqueño. En la variable sobrevivencia se encontró diferencia estadística significativa, el mayor número de vitroplantas aclimatadas y enraizadas se dio con el empleo del sustrato de tierra de sembrado siendo superior y alcanzando un $80 \%$ de plantas aclimatadas de plátano maqueño.

Cuadro 3. Promedios de longitud de raíz mayor, diámetro, altura y sobrevivencia, evaluados a los 21 días después de establecidos en el invernadero de plátano variedad maqueño (Musa balbisiana)

\begin{tabular}{ccccc}
\hline Tratamientos & $\begin{array}{c}\text { Longitud de raíz } \\
\text { mayor }(\mathbf{c m})\end{array}$ & $\begin{array}{c}\text { Diámetro } \\
(\mathbf{c m})\end{array}$ & $\begin{array}{c}\text { Altura } \\
(\mathbf{c m})\end{array}$ & $\begin{array}{c}\text { Sobrevivencia } \\
\text { \% }\end{array}$ \\
\hline $\mathrm{T}_{1}$ & $6.10 \mathrm{a}^{\dagger}$ & $0.60 \mathrm{a}^{\dagger}$ & $10.7 \mathrm{a}^{\dagger}$ & $8.0 \mathrm{a}^{\dagger}$ \\
$\mathrm{T}_{2}$ & $4.50 \mathrm{ab}$ & $0.50 \mathrm{a}$ & $5.6 \mathrm{ab}$ & $7.5 \mathrm{a}$ \\
$\mathrm{T}_{3}$ & $1.05 \mathrm{~b}$ & $0.15 \mathrm{~b}$ & $1.3 \mathrm{~b}$ & $2.0 \mathrm{~b}$ \\
$\mathrm{~T}_{4}$ & $5.30 \mathrm{a}$ & $0.40 \mathrm{a}$ & $5.7 \mathrm{ab}$ & $6.5 \mathrm{ab}$ \\
\hline C.V. & $38.6 \%$ & $28.3 \%$ & $37.5 \%$ & $32.8 \%$ \\
\hline
\end{tabular}

${ }^{\dagger}$ Promedios con letra distintas difieren estadísticamente según la prueba de Tukey $(\mathrm{p} \geq 0.05)$.

\section{DISCUSIÓN}

Los resultados obtenidos en el establecimiento aséptico de las yemas de plátano maqueño son similares a los reportados por Canchignia y Ramos (2004), al trabajar con plátano barraganete, quienes utilizaron 20 $\%$ de cloro y $0.1 \%$ de bicloruro de mercurio alcanzando un $100 \%$ de explantes sanos.

Se pudo obtener una gran cantidad de explantes sanos por el efecto del tamaño de las yemas ya que se trabajó con un tamaño de $5 \mathrm{~mm}$ el cual se pudo ejercer un control eficiente de bacterias endógenas que presentan las Musas, esto concuerda con Sandoval y Muller (1985), quienes manifiestan que el porcentaje de contaminación no es mayor al $15 \%$ cuando los explantes son de $1 \mathrm{~mm}$.

Para la regeneración de brotes en maqueño se procedió a evaluar después del segundo subcultivo lo cual se pudo obtener hasta 2.5 brotes por explante, esto difiere con lo obtenido por Canchignia y Ramos (2004) quienes en plátano barraganete obtuvieron 5.25 brotes por explante al utilizar en la fase de multiplicación, concentraciones de $2.5 \mathrm{mg} \mathrm{L}^{-1}$ de BAP $+0.8 \mathrm{mg} \mathrm{L}^{-1}$ AIA. Este efecto se debe principalmente a la variabilidad que existe entre una misma especie 
y a las concentraciones hormonales que ejercen de distinta manera para cada individuo, lo cual concuerdan con Conam (2005), quien expresa que la población de una especie vegetal, no existen individuos que tengan la misma información genética (ADN), que se conoce como variabilidad genética, lo que influye a la variación de las concentraciones hormonales en la regeneración de brotes

Una vez obtenidos los brotes fueron transferidos a medios de cultivos con diferentes niveles de sacarosa que ayudan al desarrollo de las vitroplantas. Para esta fase el mayor vigor alto se presentó en el testigo, lo que demuestra que esta variedad no requiere de suministros extras de sacarosa para su desarrollo, esto difiere por lo expresado por Daniels et al. (1997), quienes indican que al adicionar al MS concentraciones de sacarosa al $8 \%$, se favorece el crecimiento de microtubérculos en papa in vitro.

Al medio de cultivo de Murashige y Skoog se añadió carbón activado para favorecer la emisión de raíces, tornando una contextura oscura el medio nutritivo, permitiendo el desarrollo y crecimiento de la planta, obteniendo para esta investigación el mejor resultado el testigo, esto concuerda con Roca y Mroginski (1991), quienes manifiestan que el carbón activado se ha usado, para superar problemas específicos de oxidación los cuales se asocian con en cultivo de tejidos en musáceas. (Daniels et al., 1997) indican que la adición de estas sustancias al cultivo de embriones promueve su desarrollo cuando este ha sido inhibido, ya que al parecer absorbe del medio los compuestos fenolitos, auxina y citoquininas que inhiben el desarrollo del embrión somático.

En la aclimatación y enraizamiento de las vitroplantas se trabajó bajo condiciones de invernadero y así tener un mayor prendimiento de plantas, obteniendo el mayor porcentaje de supervivencia para el sustrato de tierra de sembrado con un $100 \%$, esto difiere con Canchignia y Ramos (2004) que demostraron en plátano barrraganete la mayor sobrevivencia de un 97 \% con carboncillo. Además Pérez (1998) indica, en la aclimatación de plátanos y bananos se han obtenido buenos resultados utilizando sustratos en base de humus de lombriz y Compost. Para el enraizamiento ex vitro de Musas no se requiere adicionar auxinas, ya que estas especies tienen la capacidad de sintetizar sus propias hormonas y poder formar sus raíces. Concordando con Perez (1998) que no adicionan reguladores de crecimiento para el enraizamiento de Musas ya que tiene la capacidad de sintetizar sus propias auxinas.

\section{CONCLUSIONES}

De acuerdo a los resultados obtenidos en la presente investigación, se logró establecer un protocolo para la propagación in vitro de plátano variedad, maqueño (Musa balbisiana), en el establecimiento aséptico, el mejor resultado se obtuvo en el tratamiento $20 \%$ de cloro $+0.1 \%$ de bicloruro de mercurio, la utilización de auxinas y citoquininas el tratamiento $5 \mathrm{mg} \mathrm{L}^{-1} \mathrm{de}$ BAP $+1.2 \mathrm{mg} \mathrm{L}^{-1}$ AIA con un valor promedio de 2.5 brotes, el nivel de sacarosa, se evaluó el vigor y la altura de brotes obteniendo como resultado en variable vigor se demostró en el tratamiento dos con un $61.47 \%$ de plantas vigorosas.

\section{LITERATURA CITADA}

Bidwell, R.G.S. 1993. Fisiología Vegetal. (Acción de las hormonas y Reguladores del crecimiento). Ontario, CA. A.G.T editor S. A. Primera edición. c.23. pp. $598-619$.

Canchignia, F. y Ramos, L. 2004. Micropropagación de plátano variedad barraganete. Laboratorio de Biotecnología vegetal. Universidad Técnica Estatal de Quevedo. 6pp.

Conam. 2005. Variabilidad Genética (en línea). Lima, PE. Consultado el 24 Oct. 2005. Disponible en: http://portalagrario.gov.pe/rrnn_gene.shtml

Daniels, D., J. Perez, P., y Agrmonte, D. 1997. Efecto del cultivo in Vitro en la tuberización de la papa (S. tuberosum L variedad Désireé). Trabajo Diploma, Facultad de Ciencias Agropecuarias, IBP, UCLV, Santa Clara, V.C., Cuba.

Izco, J. 1997. Botánica. Madrid: McGraw-Hill/ Interamericana de España, S.A., $1^{\mathrm{a}}$ ed., disponible en biblioteca en carta 2005 de Microsoft Corp.

Marassi, M. A. 2004. Hormonas Vegetales (en línea). Chaco, AR, consultado el 6 de diciembre del 2005. Disponible en http://www.biología.edu.ar/ plantas/hormonas.

Murashige, T. y Skoog, F. 1962. A revised medium for rapid growth and bioassays with tobacco tissue cultures. Physiol. Plant. 15: 473-497.

Pérez, P. 1998. Propagación y mejora genética de plantas por biotecnología. p. 9

Roca, W., Mroginski, A. 1991. Cultivo de Tejidos en la Agricultura. Fundamentos y Aplicaciones. CIAT Centro Internacional de Agricultura Tropical. Capitulo \# 22 Micropropagación de Plátanos y Bananos. pp. 496 - 510.

Sandoval, J. y Muller, L. 1985. Influencia del tamaño del explante en la propagación in vitro de cuatro cultivaciones de Musa. VII Reunión de la ACORBAT. San José, Costa Rica. Vol. 21. pp.87-97 
Surga, J. y Haddad, O. 1984. Regeneración de Plantas de Musaceas utilizando las Técnicas en Cultivos Meristemáticos. Jornadas Agronómicas, 11. Maracaibo. Consultado el 2 de Diciembre del 2005. Disponible en: www.redpav.fpolar.info.ve Usui, K., Okabe, K., Pernillo, R., y Ramírez, A. 1996 Principios Básicos del Cultivo de Tejidos Vegetales. Guatemala ICTA/JOV. pp. 1, 87. 